\title{
Portals to the world: technological extensions to the boundaries of the home
}

Article

Accepted Version

Ewart, I. and Luck, R. (2012) Portals to the world: technological extensions to the boundaries of the home. Interiors: Design, Architecture, Culture, 3 (1-2). pp. 7-22. ISSN 2041-9112 doi:

https://doi.org/10.2752/204191212x13232577462457 (special issue 'Special effects: technology and the interior experience') Available at https://centaur.reading.ac.uk/28817/

It is advisable to refer to the publisher's version if you intend to cite from the work. See Guidance on citing.

Published version at: http://www.ingentaconnect.com/content/berg/idacj/2012/00000003/F0020001/art00002

To link to this article DOI: http://dx.doi.org/10.2752/204191212x13232577462457

Publisher: Berg

All outputs in CentAUR are protected by Intellectual Property Rights law, including copyright law. Copyright and IPR is retained by the creators or other copyright holders. Terms and conditions for use of this material are defined in the End User Agreement.

\section{www.reading.ac.uk/centaur}

\section{CentAUR}


Central Archive at the University of Reading

Reading's research outputs online 


\section{Portals to the World: Technological Extensions to the Boundaries of the Home}

lan Ewart is a Research Assistant in the School of Construction Management and Engineering at the University of Reading. After a career in engineering, he switched to anthropology to pursue interests in material culture studies, and technology generally. He graduated with a BA (2006) and MSc (2007) from the University of Oxford, where he is finishing his DPhil in the Anthropology of Engineering.

Contact: i.j.ewart@reading.ac.uk

Dr Rachael Luck is an architect, design researcher and lecturer in the School of Construction Management and Engineering at the University of Reading. Rachael is an editorial board member for Design Studies, with editorial input into the book About: designing, what goes on in design team meetings (Taylor and Francis, 2009). Contact: r.a.c.luck@reading.ac.uk

ABSTRACT This article examines the ways that technological objects inside the home are viewed and productively used by a group of older people to extend their access to environments beyond the home. Beginning with a discussion of types of domestic object, we highlight appliances and gadgets, and focus our attentions on the latter. The changes in life brought on by ageing, in particular a reduction in mobility, provide the context for our study, in which access to the outside world becomes increasingly difficult. Recognising their changing circumstances led our participants to actively and selectively engage with these objects, mitigating the shrinking of their accessible environment by using them as a gateway to the many virtual worlds now available. We coin the term 'portal objects' to describe the potential that this type of technological object provides, and suggest that the investigation of interiors can be enriched by recognising and including the worlds outside that become integral to occupation inside.

KEYWORDS: technology, environment, objects, older people. 


\section{Portals to the World: Technological Extensions to the Boundaries of the Home}

\section{Introduction}

The proliferation of household technologies in recent years has provided inhabitants with new ways of engaging with their home environment. Modern homes are becoming more electronic, either in their fabric, or through the introduction of devices into the interior. Whereas much of the framing of these household technologies is around the effects they have on the domestic life of working people, this is not an imperative for all sectors of society. This article is an attempt to describe and analyse how one particular group of people has engaged with the technological world. It happens to be a group of older people, and provides a specific set of data, since the significance of technology inside their home is increasingly predicated on notions of healthcare and 'ageing-in-place'. Chan et al. (2008) for example, provide a wideranging and comprehensive study of the current status of research into technology in the 'smart' home. They begin with the assertion that "in the era of information technology, the elderly and disabled can be monitored with numerous intelligent devices" noting that: "in particular, technology can help persons age at home in safety and independence" (2008:55). Similarly, as pointed out by Salovaara et al. (2010), research on the use of information technology by older people tends to "focus on the deteriorating motor, sensory, and cognitive skills and how they relate to the abilities to use computers efficiently" (2010:808). Their conclusion was that the use of modern communication technologies is made as a deliberate choice to enhance the experience of life transitions associated with retirement. In our research, although ageing in place and access to healthcare services were sometimes discussed, it was not the dominant context for interacting with domestic technologies. This was seen as one aspect of ageing, but a more common perspective was a concern with access to, and relations with, the world beyond the doorstep: to reduce distances travelled whilst maintaining social relations. As with the participants in Salovaara et al., some of our participants saw the use of technologies as an active and broadening experience, and a means by which the limits imposed by physical change could be mitigated. 
This research forms part of the 'Living Futures' project currently being undertaken by the authors, which stems from an interest in understanding the ways domestic surroundings, local environments and routine encounters with material artefacts feature in the lives of older people. The participants' perceptions and engagements with technology in the home, as self-defined in various forms, were integral to this study. To investigate this, we spent around 20 hours in conversation with a group of six older people, four female and two male, aged 69 to 88, in their own homes and introduced a photographic exercise. Each person was provided with a camera, and asked to take photographs in response to questions about their home life and interactions with technology. All the figures used in this paper are photographs made by the participants. These photographs were then used in a process of elicitation, to remind the participants of their responses and as a focus for recorded conversations. In contrast with an agenda-driven semi-structured interview, this approach intentionally provided prompts for self-reflection on what they saw as important in their lives.

Not everyone engaged fully with the use of a camera to provide visual answers to lifestyle questions, "We know what it [a reclining chair] looks like, so why do we have to take a photograph of it? And ... privacy in your home, how can you photograph that?" Other people creatively engaged with this task, taking photographs of abstract concepts, such as the time 'wasted' on domestic chores and also appropriated the task using the Internet to find images of things, to represent the objects and aspects of their lives they considered important. The combination of methods provided a variety of ways to engage with our participants and a rich suite of data to draw on.

Anecdotally, older people are sometimes seen as fixed in their behaviours, and less flexible in their attitudes to adopting new practices. The onset of old age has inevitable consequences, including reduced mobility. The thrust of this paper is to suggest that older people appropriate technological objects in a way that counters the restrictions of reduced mobility. Specifically, as a way of engaging with the world outside, as their own world becomes socially and spatially limited, through what we refer to as portal objects. 
The first part of the paper clarifies the type of object that may constitute a portal object, by reference to other possessions and domestic technology generally. While the creation of the category is somewhat arbitrary, the effect on perceptions and practices can be seen in the lives of our participants, so we feel justified in suggesting that this is a phenomenon worthy of further investigation. In particular these objects play a role in countering the restricting effects of reduced mobility, which are described in the second section. What we term 'the shrinking environment' is a very real effect for older people, illustrated by their descriptions of the risks involved in carrying out everyday activities, and the concentration of social relations a process that extends beyond the interior of the house and reconfigures relations with the world outside. Reduced mobility gradually decreases the size of their effective environment, altering the mechanisms for social interaction, making distant friendships and family encounters more difficult to maintain. But as these barriers draw closer, the plight of our participants is eased by their ability to construct new practices and relations through the use of technologies. Rather than passive acceptance of the inevitability of their own demise, our participants saw their present situation as part of life's journey, and used technologies to replace, enhance or reinvent previous ways of living.

This active appropriation is described in the third section, with examples of our participants making deliberate decisions about whether and how they use these portal objects, breaking the stereotype of older people as hapless recipients of electronic media. Through a conscious process, they can overcome difficulties of their changing circumstances by using electronic devices to enter into alternative worlds, as discussed in the final section of the paper, a means through which engagement with the world is continued in a different way.

\section{Domestic Objects}

Possessions fill our interiors, surrounding us with their physical presence, evoking emotions and guiding behaviour (Miller 2001). Having things inside the home is a practice that constitutes more than simply possession; different sorts of value are imposed onto and created by our various artefacts. "The interior - as a human artefact - is a manifestation of time, space, and people; of cultural values and belief systems; and of social structures, new technologies, and philosophies of beauty" 
(Massey and Turpin 2010:5). Photographs evoke memories and demonstrate significant associations; the detritus of past tourism provides a tangible link to other places; favourite furniture moulded and coloured by years of use; all these things provide conduits of evocation, connections to different times and places. For Cieraad the accumulation and interpretation of possessions is a result of a process of continual home re-invention, until "when growing old...eventually the lifetime cycle of home inventions will come to a creaking standstill" (2010:94). From this perspective, older people are no more than curators of objects and memories. We would contend that the home does not so easily lose its relevance, and that the older people we talked to saw themselves in their own world, and not simply as custodians of objects.

However, in creating their own world, the members of our study group were increasingly disinterested in the aesthetics of their interiors. As one participant said, when discussing recent electrical work left undecorated; "I'm not concerned about it, as long as it's working, the switch is working and the lights are working, l'm not really all that bothered". This is contrary to the view of an ambition to create a deliberate 'style'. Olesen (2010), for example, describes the accumulation of particular objects as a deliberate attempt to create moods inside the home, and reflect the owner's chosen taste. For her, the creation of 'atmosphere' was a result of a careful selection of objects as decorative items that released a conceptual iconography: ethnic objects representing idealised exoticism. These evocative and charismatic objects have the potential to alter our moods without us being aware of what they are doing, what Miller refers to as 'the humility of things' (1987:85-108). He suggests that objects can create a framework for emotional response without necessarily acting directly, providing subtle cues while remaining humbly in the background. In our study group, these 'humble things' were supplemented by objects with the capacity to reconfigure relations with the home and the world outside; the technological things we call portal objects.

In the same way that decorative, and emotive objects could be said to evoke particular reactions and behaviours, the thrust of our thesis is that some technological objects also achieve a response but in a different way. Their potential lies not in their charisma, or their ability to catalyse an emotional response, but in their capacity to act as a gateway to new experiences beyond the interior. This 
category of technological objects in other words, acts in a different way to most of the material culture of the home, since they can be used to transport us to different worlds, in an almost literal way. The interaction between our participants and these objects falls into what Sparke identifies as the "social, cultural and psychological links between interiors and inhabitants" (2010:8).

At this point we need to clarify what we mean by the term 'technological objects', at least as used in this context. Technology underwrites everyday life, to the extent that it is now difficult to define it as a discrete category. So many things are now 'technological' that the term becomes almost meaningless. Intuitively there is a difference between for example, a dishwasher and a computer, despite the fact that both are electronic and microprocessor controlled, and both are household objects. Similarly we might associate a microwave more closely with the dishwasher than the computer, on the basis that both are appliances and intended to fulfil specific household tasks. These are not the sort of objects we focus on in this paper. The essential distinction we wish to make is between appliances and gadgets. Appliances display more of Miller's 'humility', fading into the background in a gentle hum or occasional beep, and requiring relatively short-term interaction. Once the dishwasher is loaded and switched on, our dealings with it are almost over, and its on-going presence is largely unnoticed. Appliances are essentially unobtrusive, and usually come into view only as their purpose requires. This was a distinction also made by our participants, for example in describing a washing machine and dishwasher: "I do like that part of technology that saves you time, you know, 'cause I don't want to stand washing clothes. I don't want to get back to nature, really!"

Figure 1 goes here

Figure 1

Attention-seeking objects

Other electronic objects, 'gadgets', are less humble and more demanding of our attention. They differ from 'appliances' in two fundamental respects, both of which will prove significant in our later discussion. Firstly, interaction with gadgets is responsive, allowing access to information and the opportunity to affect the type of information provided, through a continual process of observation and reaction. 
Televisions come to life through broadcast programmes and guides, computers through operating systems or the Internet, games consoles through their software. Navigating and accessing this variety of outputs depends on systems of control, through a range of devices that signify our intentions: the TV remote, games controllers, keyboards and so on. Secondly, gadgets demand chronic attention: individual periods of use are significantly longer than would be the case with appliances, and the frequency of use is likely to be higher. In many ways this is a fundamental characteristic, since it entices users to immerse themselves in the worlds that are accessed through the gadget. "[photograph] four was the computer, which I do use a lot as well. I mean, that's technology and that's the Met Office site, which shows me if it's going to rain when l'm going to walk the dog in the next 20 minutes or so".

Figure 2 goes here

Figure 2

Immersion in the other worlds

For Alice the computer requires an active and extended engagement in her decision whether and when to leave the house, and how this impacts on the rest of the day. She could have simply looked out of a window and decided whether or not it might rain, but given the facilities to make what she perceives to be a more accurate and long-term prediction, she immersed herself in the virtual world of maps and raindetecting radar, as displayed on the screen.

Trying to distinguish between 'appliances' and 'gadgets' is of course open to interpretation, and it would certainly be true to say that there are many technological objects in the home that we would struggle to classify. However, this is an attempt to suggest that domestic objects which are generically referred to as 'technological' do in fact deserve closer consideration, as much for their effects as for their complexity or materiality. Perhaps the best way of defining the objects of our interest, comes from one participant who referred to this type of electronic device as her 'little fantasy': "They're all very different sorts of things to the other things ... you know, we started off with robots and iPads and now we're talking about walk-in baths and stair lifts. Practical, purely practical stuff. I mean, the other stuff was ... my little fantasy 
that maybe I could have a robot that would do it. So the first question is kind of fantasy and the second one is sort of reality and being practical about things".

The fantasy of gadgets comes through their ability to allow us to reconfigure our relations with the world, to incorporate the worlds we see through them, transcending the interior and providing access to a different kind of exterior. In our study, this was clearly an important aspect of the participants' perception of these objects.

\section{The Shrinking Environment}

The people who were the participants of this study commented on the effects of ageing on their mobility. This was made manifest through discussions about how their ability to explore the world was increasingly curtailed by frailty: "What's the point of going on holiday and staying somewhere for nothing? There's no good reason, is there? You can't go walking or anything thereabouts ... I mean, it's just the facts of life, isn't it? These things happen".

Seen from the perspective of an older person, the environment becomes fraught with risks, even in a leisurely afternoon by the river: "On one of these occasions, I was standing [fishing] and waiting for the wonderful bite that was to come, on the banks of the River Thames at Mapledurham, it was sloping. Well, I turned slightly, and I started to feel myself going backwards, you know, and a friend of ours was round, and he said, 'Mabel, oh dear, you're falling over" and I was going, "dah, dah, dah," and then I got to the river and went "splash" fell on my - and totally in the water ... suchlike things have happened to me on real occasions, so, you know, I think you're worried about it".

The accessibility of the environment to our participants was threatened in two ways. First, a physical change in mobility means that the world becomes a more risky place, and secondly the social environment potentially becomes impoverished. The physical environment becomes more of a challenge to older people as their mobility is reduced; this is a primary factor in determining the extent to which elderly people are able to engage with their neighbourhood (Moorer and Suurmeijer 2001). Simple things like standing beside a river become activities that need to be undertaken with careful consideration. Hazards outside the home become more substantial and even 
insurmountable: "we don't have a lot of traffic, only in the morning and in the evening. But even so, I don't think an old person, even as old as me, I'm not very good at mobility and, you know, l'm not very good at balancing and walking and some things, so I would hesitate to walk across the road to talk to somebody. And I can't - I might get stuck halfway or I might, you know".

Figure 3 goes here

Figure 3

An insurmountable obstacle

At a certain point, the act of crossing the road became too risky to even attempt, effectively cutting off the area on the other side. Similarly, to be able to walk along the path becomes difficult when the path is partially blocked by cars, and the paving slabs are broken and uneven. "Well, the footpaths, over the years, have been broken by the weight of vehicles on them and could be quite dangerous ... There must be some limit, and if there's a step of half an inch or an inch in the pavement, they do something about it, but it has to get quite bad or someone has to fall over and hurt themselves before anything's done". Before even thinking about crossing the road, this presents an obstacle to overcome immediately outside the front door.

Figure 4 goes here

Figure 4

Obstacles in the neighbourhood

Physical barriers are not exclusively in the domain of public space, as one participant described restrictions in her own garden: "I don't tend to climb up outside in the garden when there's no one around, because it's a big garden and if people don't know, sort of, especially between the two sunrooms, if they're not in there, I could fall and no one would know. So I do tend to wait until there's someone around".

For these participants, the immediate surroundings were seen as part of a specific person-centred experience of the world, in a similar way to Imrie's (2004) description of perceptions of the home for people with disabilities. To paraphrase him, the world is not designed for people with impairments, whose life consequently revolves 
around resolving issues of functioning in unsuitable spaces (2004: 761). The width of the road becomes an issue for a person unable to cross quickly enough, and an uneven path becomes a serious hazard. As mobility is reduced, potential barriers increase in number and decrease in size.

Secondly, as well as the physical environment shrinking, the social environment is also put under stress. Previous studies have suggested that older people tend to focus their social interactions more acutely on a smaller circle of friends and family, especially their offspring and grandchildren (Dahlin-Ivanoff et al. 2007). This was certainly the case among our participants:

So is it by coincidence that your sons and daughters have moved relatively close? They all came here.

Did they do that deliberately, because you're here, or was that just, sort of, work commitments?

Well, they would say, "No," but I think it probably did have a factor.

For various reasons, including the death of old friends and the difficulties of maintaining long distance relationships, the social environment was also prone to shrinking: "I mean, I've got a friend down in Wales that I go and stay with ... but I couldn't do all of that by train ... I've got a friend at Melksham in Wiltshire, which is much more difficult to get to, so... it would have to be train or taxi, I suppose. Or train and bus and it wouldn't be as easy [as driving]".

This is not to say that our participants were helpless in offsetting these effects, and in fact the trend to embracing communication technologies seems to be an effective strategy in mitigating a reduced social environment, as Harper has previously noted (2010: 230). Evidence for this can be seen comparing studies of the scope of social interaction among older people. In a study from Italy, older people were reported as having a satisfactory social life: "Contrary to the general image of aging as a period of decline and hardship, the research has shown that there is social integration, which copes with loneliness" (Cavallero et al. 2007:100). This compares markedly with a study from 20 years previously in Britain, which showed the older participants had "significantly lower levels of social involvement" (Morgan et al. 1987:807). Our 
suggestion is that this movement is to do with the development and active appropriation of technologies that counter the effects of social isolation. The use of the Internet, satellite TV, mobile phones and so on, provides access to the wider world from the inside of the home.

The members of our study group reported altered relations with their home and neighbourhood. The days of extensive travel were behind them, and for some the difficulties of even local travel were becoming apparent. Living independently becomes a function of the world inside the home and the opportunities that offers, with less desire or capability to experience the wider world. This is where the use of gadgets as portal objects becomes a significant activity.

\section{Active Choices}

Increasing age produces a set of circumstances that was seen to redefine the home, including (sometimes unwanted) interruptions to the privacy of the interior by health professionals, and concerned family and friends. Rather than being a place of personal sanctuary, the home becomes increasingly associated with individual confinement (Imrie 2004). The shrinking social and physical environments described in the previous section presented our participants with a dilemma. All of them had a sharp mind and a desire for a fulfilled daily life, but were restricted in how they could achieve this. Moving outside the home environment had become increasingly difficult, so life inside was supplemented through the use of portal objects in a deliberate and active way.

Participants were not passive recipients, but made active decisions to use technology to provide an opening to the wider world. Watching television was not an exercise in pointless time-filling, but was part of a conscious effort to use the medium for a specific purpose: "because we're as old as we are now, and that's the only reason, 'cause we never used to look at it [the TV] and we look at it quite a lot. And it's wonderful to be able to look at all the sport that we can see in faraway countries and in the dark and dismal winter, you can turn it on and you can see games going on in the sunshine and people enjoying themselves and it's just wonderful to be able to have that facility". 
Choices of television viewing for example, were made in response to specific situations encountered inside the home. Contrary to the suggestion made by Birkeland and Natvig (2009), that older people cope with issues of illness and loss of mobility by resigned and passive acceptance, it seems to us that activity is a far more accurate descriptor of the practices being carried out. In their words: "television and radio are very important. They hear a voice or music in the radio, and they can see faces and get information and impressions from the world outside on the television" (2009:262). We would see this as a rather more active engagement, since our participants were not inert but made choices that suited their mood and purpose.

Figure 5 goes here

Figure 5

One route to the world outside

Even the deliberate and basic choice of whether or not to use these objects was one that many participants alluded to: "I've got this thing about well, as little [technology] as possible ... you know, there's certain things that I wouldn't be interested in or come into contact with, well, so that doesn't bother me". Despite the fact that for many living inside was a major part of their daily life, this is not to say that the choice of activity was restricted to gadgets and technology: "well, I don't know why I don't like it [the TV], but to me l've always got something interesting".

The generation we were talking to had, of course, spent most of their lives without these choices. Many people described hobbies and activities in their past and decided whether or not they continued them: "I was always knitting and I was always making things for them you know, making dresses and whatsaname, and things like that".

Alternatively some people replaced old ways with activities enabled by new ones based on modern technologies: "my son bought me a Kindle for Christmas, which is lovely ... because I can download free books that are you know, out of copyright, but I still read a book. But I can envisage that that would be really helpful in the future because, if l've got a thick book, because my fingers are holding it ... that there will 
come a time that maybe - and you can make the print as big as you like and it's got a non-reflective [screen]".

As is clear from our study group, even when life became centred on the home, this does not mean that they resort to a blanket use of technology to fill the day. Life inside still presents possibilities for maintaining and developing social relations, and the ability to encounter the world beyond the home in a selective way. It may be easier to experience the sunshine in another part of the world than the other side of the road, albeit in a more remote way. Having such a range of choices allows the users to make deliberate decisions about how and when to use the gadgets they own.

Figure 6 goes here

Figure 6

Using technology to supplement daily life

\section{Portals to Other Worlds}

Key to this argument is that the technological objects we refer to as 'portal objects' have the potential to engage and provide access to different worlds outside the home. In the way that Birkeland and Natvig describe the use of the telephone as 'bringing relationships into the home' (2009:261), the use of certain objects extend the home environment by incorporating other people and places into the interior. As with the case of television viewing, the people in our study made a conscious decision what to watch and were not hapless recipients of broadcast content. To do this requires immersion into the 'medium' of a portal object, the programme, the Internet, the game and so on. These are the attention-seeking objects discussed before, that require the user to demonstrate attentiveness to the worlds presented to them.

From inside the home, interactions with the world outside are often mediated by a view from a window. This is a framing that provides privacy but restricts access. For older people, this is evidently an important aspect of their life. The interior of the house provides a context for engagement with the outside world, experienced by viewing it remotely. "So I get on the [exercise] bicycle and you often say, 'Who have 
you seen?' I say, 'Nobody'. 'Oh, yes, I did see somebody hobbling past to get to the bus stop'. You know, that's about it. Oh, and one or two dog walkers, you know, and there's a little old dear who walks by carrying her shopping like. I keep wanting to rush out and say, 'Stop. Look, can't you get something that will carry your shopping along better than that?"'

Seeing the world in a framed way, yet removed from physical engagement, can be perceived as viewing the world from within. The worlds provided by portal objects act in a similar way: often presented as screen displays, framed to provide a limited view, but allowing the opportunity to expand on that view by navigating the medium of a virtual world beyond. Most obviously, through television: "We've been watching the cricket, of course, and the tennis, which is going on in Miami at the moment and it is just wonderful to be able to do that".

While television is a commonplace example of a virtual world accessed through a portal object, there are many others. With the development of video communications such as Skype, a more personal virtual world can be brought inside. For our participants, this was one means of maintaining family contacts: seeing and being seen, with real-time interaction with another place in the world. This engagement in the activities in another location was literal, since what was happening in one setting was consequential for activities in another space: attracting people to the camera and moving a camera to show and share something with other people in a remote location. Several people described how the use of Skype had become part of their lives and for one person to keep in contact with her son in Australia: "[Skype] isn't clear enough and then, they all have to sit in a, sort of, set way. Well, I know you can go into the garden and take the children there and that's something, but we decided not to do it ... Maybe it was an inferior laptop, if you want to do Skype, maybe you'd get a better one". Although sometimes viewed critically, Skype is one means to access to real worlds that are virtually experienced.

Another form of engagement is with virtual worlds that are encountered through games consoles. Interaction with these worlds is through actions in the home environment that correspond with the movement of an avatar portrayed on a screen. To keep body and mind active one of our participants was an advocate for the 
Nintendo Wii: 'there's a games one as well that's on there that you can play table tennis, which is - it's actually just like playing table tennis and you don't have to be that physical, you could just stand there and do it like this". This medium allows a user to envision movement within a virtual space; the object acts as portal to another world, without actually leaving the home.

As Dahlin-Ivanoff et al. began "starting with the basic insight that ageing in place is more than mere living in an objective physical-spatial context" (2007: 25), after engaging in conversation with our participants and their accounts of lived experience, so we end up. Individual lives within the home are mediated by the use of objects that have the capacity to expand the real world into other places: virtual worlds where existing relationships can be developed and new ones created.

\section{Conclusions}

Technological objects are different from many of the objects found in the home; they do not represent memories or markers of identity. Our research suggests that the use of some technologies represents an active desire to embrace the wider world and maintain an active engagement with it. Portal objects are incorporated into domestic practices in a way that blurs the boundaries between the inner world of the home, and the external environment. Portal objects can be viewed as having the means to extend the potential boundaries of the home.

For the older people who made up our study group, instead of succumbing to the apparent reduction of their world, they have been able to see technology as a gateway to a wider world. Talking on the phone, using the Internet, Skype, playing games and so on, were all means by which our participants overcame a reduction of physical capabilities to maintain engagement with the world outside their home and relations over physical distance. While our study group was made up of older people, who for various reasons are more dependent on the interior of their home than many, the concept of certain technologies acting as portals to alternative worlds is by no means restricted to them. McDowell's description of the social pressure on working mothers illustrates another context (2007). Various portal devices such as webcams and communication systems served to maintain contact between the mother at work and the child at home, allowing access from one world to another. 
Objects in the domestic interior have been seen in various ways, often on the basis of their potential to enhance our lives through their aesthetics or meaning. The discussion presented here suggests that the response to technological objects in the home is different from other possessions, and requires new ways of thinking, of which the portal concept may be one.

\section{References}

Birkeland, A. and Natvig, G.K. 2009. Coping with ageing and failing health: A qualitative study among elderly living at home. International Journal of Nursing Practice 15: 257-264.

Cavallero, P., Morino-Abbele, F. and Bertocci, B. 2007. The social relations of the elderly. Archives of Gerontology and Geriatrics 44(1): 97-100.

Cieraad, I. 2010. Home from home: Memories and projections. Home Cultures 7(1): 85-102.

Dahlin-Ivanoff, S., Haak, M., Fange, A. and Iwarsson, S. 2007. The multiple meaning of home as experienced by very old Swedish people. Scandinavian Journal of Occupational Therapy 14: 25-32.

Harper, R.H.R. 2010. Texture: human expression in the age of communications overload. London: MIT Press.

Imrie, R. 2004. Disability, embodiment and the meaning of home. Housing Studies 19(5): 745-763.

Massey, A. and Turpin, J. 2010. Editorial introduction. Interiors 1(1-2): 5-6. 
McDowell, L. 2007. Spaces of the home: Absence, presence, new connections and new anxieties. Home Cultures 4(2): 129-146.

Miller, D. (ed.) 2001. Home Possessions: material culture behind closed doors.

Oxford: Berg.

Miller, D. 1987. Material culture and mass consumption. Oxford: Blackwell.

Moorer, P. and Suurmeijer, T.P.B.M. 2001. The effects of neighbourhoods on size of social network of the elderly and loneliness: A multilevel approach. Urban Studies 38(1): 105-118.

Morgan, K., Dallosso, H.M., Arie, T., Byrne, E.J., Jones, R. and Waite, J. 1987. Mental health and psychological well-being among the old and the very old living at home. The British Journal of Psychiatry 150: 801-807.

Olesen, B.B. 2010. Ethnic objects in domestic interiors: Space atmosphere and the making of home. Home Cultures 7(1): 25-42.

Sparke, P. 2010. The modern interior: A space, a place or a matter of taste? Interiors 1(1-2): 7-18. 